\title{
Novas Estratégias para o Ensino da Química 0 Grande Musical da Química
}

A professora Lourdes Leitão, no Boletim da Sociedade Portuguesa de Química Julho/Setembro 2010, lançou um apelo para a realização de actividades no âmbito do Ano Internacional da Química. Já há algum tempo tinha em mente a realização de um grande espectáculo. Para a sua consecução convidou as professoras Maria da Conceição Mendonça e Maria de Fátima Sousa e ainda o professor Jorge Vieira, que aceitaram a ela juntar-se e, em conjunto, aventuraram-se a dar vida ao projecto "O Grande Musical da Química". Contactou ainda a Dra. Regina Gouveia que se disponibilizou a colaborar em tudo o que estivesse ao seu alcance. O projecto foi apresentado à companhia "Teatro do Sol", a quem foi proposto reunir a equipa técnica necessária para ensaiar e dar forma ao espectáculo imaginado. Este grupo considerou o projecto exequível e com excelentes virtualidades, pelo que se passou de imediato, nas três escolas envolvidas, Escola Salesiana Colégio dos Órfãos do Porto, Escola Secundária Inês de Castro de Vila Nova de Gaia e Escola Secundária João Gonçalves Zarco de Matosinhos, ao recrutamento dos alunos que, num lento, desgastante, mas entusiástico processo de seis meses, se iriam transformar nos actores de "O Grande Musical da Química”.

Partimos entusiasmados para este projecto porque acreditamos que a Escola não se resume ao que acontece dentro das quatro paredes da sala de aula, onde se desenvolve um trabalho árduo na construção do saber/ saber fazer e na procura de estratégias diversificadas para poder chegar a todos e simultaneamente a cada um dos alunos. Há uma necessidade, cada vez maior, de levar os jovens a olhar à sua volta e a sentirem que nada nasce do Nada. É o conhecimento científico que lhes permite entender, procurar soluções e responder aos problemas que vão surgindo no seu dia a dia e a cada momento.

Motivar para o estudo da Química e para uma melhor compreensão do mundo que nos rodeia deve ser uma constante no quotidiano da vida de qualquer professor desta área. Os desafios que vão sendo colocados, quer aos professores, quer aos alunos, levam-nos a encarar a ciência e o conhecimento como algo aliciantemente indissociável. Impõe-se, deste modo, a procura de novas estratégias com o objectivo de levar os alunos a ser uma força viva no seu processo de aprendizagem, fazendo com que a Escola seja cada vez mais uma janela aberta para o mundo, o que permite uma permuta de saberes através de ferramentas diferenciadas, sendo o teatro um veículo potenciador desta dinâmica. O projecto tem como principal objectivo divulgar os principais marcos da História da Química, contextualizados na História do Teatro e na História Universal, celebrando as múltiplas contribuições desta ciência para a Humanidade. Trata-se de um projecto potenciador da motivação e sensibilização dos jovens para as disciplinas científicas, mas também para a História e para a Arte em geral, permitindo-lhes uma integração transversal de diferentes aprendizagens, a par do desenvolvimento de novas competências.

Enquanto o grupo de professores dinamizadores delineava o melhor ca- minho a seguir para o desenvolvimento do projecto, a Dra. Regina Gouveia, professora de $F Q$ já aposentada, com todo o entusiasmo que lhe é característico, reconhecido por todos os que a conhecem, escrevia o texto que serviu de base ao guião do musical e que intitulou "Breve História da Química". Entretanto, a Companhia "Teatro do Sol" seleccionava um conjunto de profissionais que asseguraria o apoio técnico do Musical, constituído por um encenador, uma assistente de cena, um músico, um coreógrafo e uma figurinista/cenógrafa.

As grandes pedras mestras para a concretização do projecto, Os Alunos, cerca de 60 no conjunto das três escolas envolvidas, aderiram com curiosidade e interesse à proposta; a estes juntaram-se, ainda, elementos da Banda Juvenil Salesiana de Poiares.

Surgiu a necessidade de romper barreiras interpessoais que existiam naturalmente pelo facto do grupo de trabalho ser constituído por jovens desconhecidos, provenientes de escolas distintas. Surpreendentemente, as dinâmicas de grupo implementadas superaram as expectativas, tendo-se constatado que ao fim de duas ses-

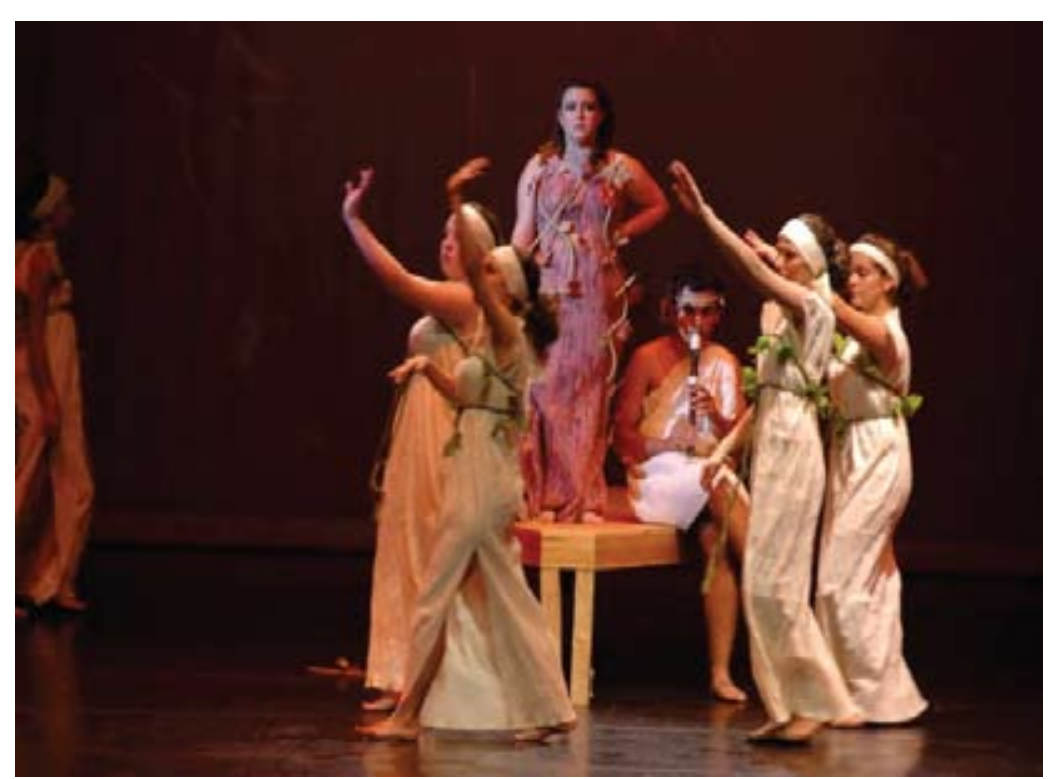

Canto a GAYA, a Deusa da Terra, com acompanhamento de flauta e coreografia de sacerdotisas 
sões já se tinha verificado uma fusão num único grupo.

Não foi fácil o início. Era sabido o que pretendíamos, mas vimo-nos confrontados com o facto de desconhecer os interesses e capacidades de cada um. Todas as competências foram aproveitadas, optimizadas e potenciadas com a ajuda dos respectivos técnicos, conseguindo-se assim rentabilizar ao máximo as valências (canto, dança, música ...) dos diferentes alunos.

O projecto foi apresentado, não só à Direcção de cada uma das escolas, como também às respectivas Câmaras Municipais e Juntas de Freguesia da área das escolas envolvidas, que identificaram no projecto "um inegável interesse, quer pela sua oportunidade quer pelo seu carácter único e formato inédito, quer ainda pelo seu sentido educativo e formativo". Tendo em conta os constrangimentos económicos actuais, na medida das possibilidades, cada uma das instituições se propôs dar uma contribuição no sentido de tornar viável a concretização do projecto.

A apresentação pública do espectáculo decorreu nos dias 20 e 21 de Junho no grande auditório do Rivoli Teatro Municipal, gentilmente cedido pela CMP.

Atendendo a que o público alvo era constituído não só por alunos mas também pelo público em geral, procurou-se utilizar uma linguagem simples e fazer uma abordagem ligeira, clara, mas rigorosa, dos conteúdos, de forma a permitir que a mensagem pudesse passar sem obstáculos.

O Musical foi apresentado em dois actos. No primeiro, partiu-se dos quatro elementos, Fogo, Terra, Ar e Água, para uma abordagem cronológica da história da química fundindo sempre que possível, com a do teatro, a Universal e com Arte em geral, e termina com Lavoisier e a Revolução Francesa. No segundo acto foi realizada uma conferência celestial de grandes químicos, onde foram apresentadas as principais descobertas de químicos como Lavoisier, Dalton, Mendeleev, Kirchoff, abrilhantadas por um chairman e respectivo tradutor, acompa-

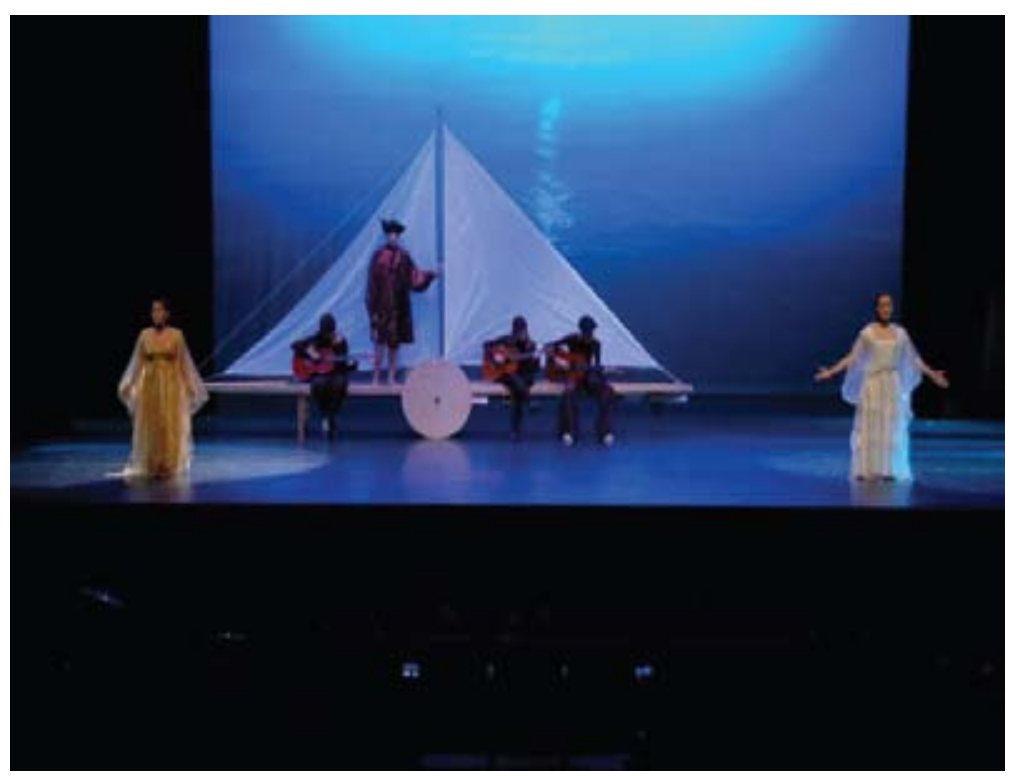

Evocando a água, e interpretando Camões, cantando "Mudam-se os tempos mudam-se as vontades" e tendo por fundo Paracelso

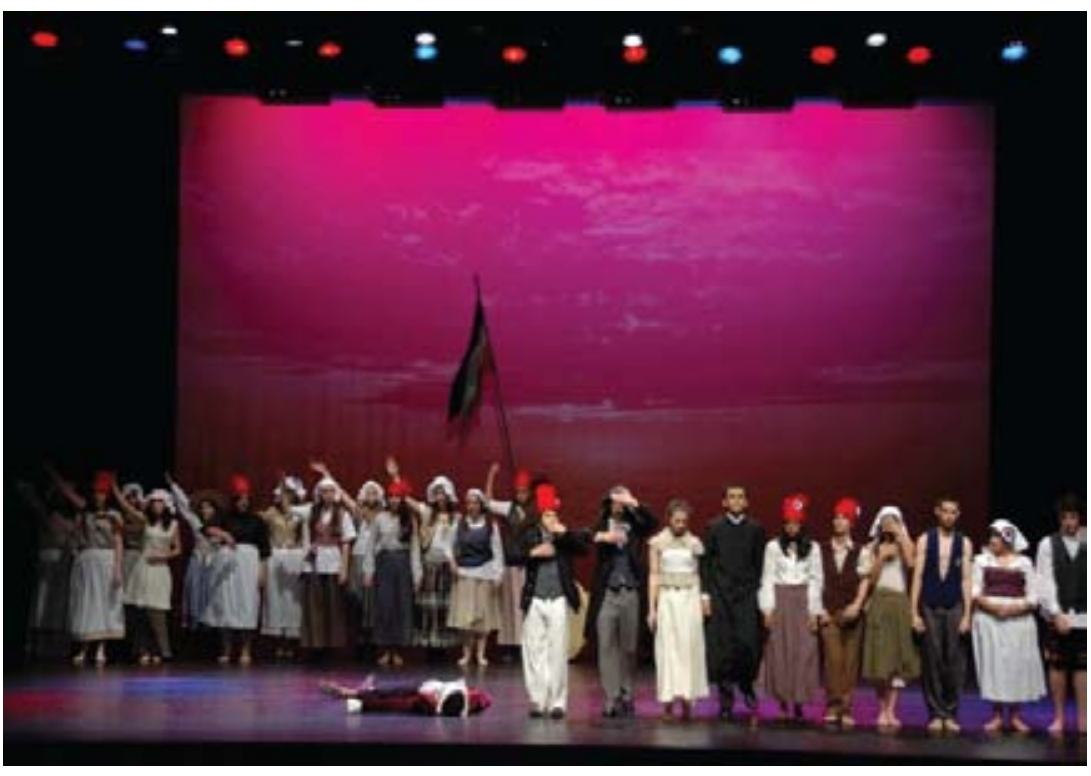

Lavoisier, contextualizado na Revolução Francesa

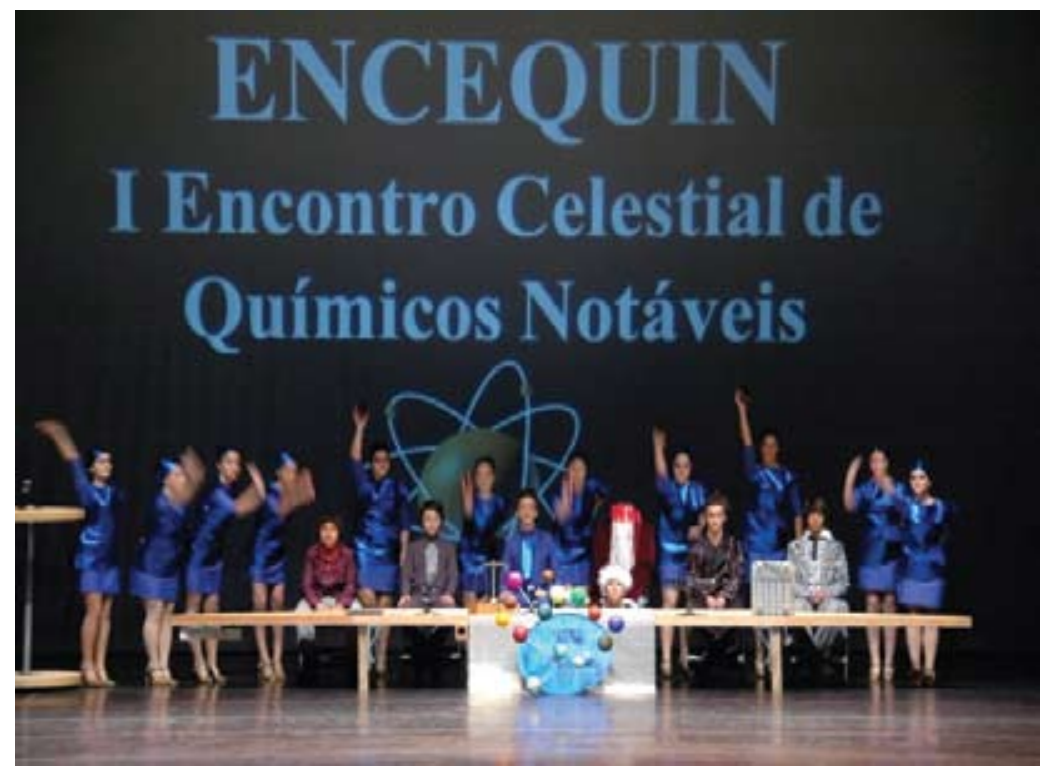

Mesa na Conferência Celestial, onde estão sentados o Chairman mais seu tradutor, Lavoisier, Dalton, Kirchoff e Mendeleev 
nhados por um grupo de bailarinas, intituladas "meninas do protocolo", que iam coreografando as diferentes teorias apresentadas. Houve ainda oportunidade, neste segundo acto, de fazer referência em apoteótico clima de festa, onde a entrega de prémios Nobel foi transportada para a nossa época (cem anos mais tarde) em jeito de entrega de Óscares de Hollywood, a alguns químicos galardoados com o Prémio Nobel da Química, nomeadamente, Fisher, Bequerel, Thomsom, Rutherford, Max Plank, Bhor e Marie Currie, pelo trabalho desenvolvido em áreas que contemplam temáticas integradas nos programas curriculares dos ensino básico e Secundário.

Tudo no espectáculo é inédito, desde as músicas e respectivas letras, até ao guião, que se foi transformando, à medida que havia necessidade de adequar os papéis às diferentes características e à evolução dos alunos.

Tanto o guião como as letras das músicas foram sendo construídos a partir de contribuições de diversos elementos do grupo de trabalho. O espectáculo tem um único suporte cénico que se vai transformando ao longo da acção. Começa por ser uma car- roça e logo se torna um barco, a seguir é um canhão, logo após é mesa de conferência e passerelle e as suas rodas são usadas pelos químicos na apresentação dos trabalhos durante a conferência celestial. Este elemento central do espectáculo foi concebido, de uma forma brilhante, pela cenógrafa e figurinista Olga Rego.

\section{O Grande Musical da Química foi} um sucesso e um excelente veículo de divulgação da Química, tendo-se mostrado gratificante para os dinamizadores e alunos/actores, uma vez que os objectivos propostos foram parcialmente atingidos, atendendo a que as datas disponibilizadas pelo Rivoli Teatro Municipal coincidiram com o final do ano lectivo e o início dos exames nacionais, o que impossibilitou a presença do público-alvo principal, alunos do $3^{\circ}$ Ciclo e Secundário. Foi sem dúvida uma oportunidade de crescimento dos alunos e motivação não só para a química como também em outras áreas.

O Grande Musical da Química representa ainda uma mais-valia para qualquer espectador, independentemente da sua idade.

\section{ConclusÃo}

Consideramos que este projecto tem qualidade para ser apresentado, noutras cidades, a outros alunos, mesmo para além do âmbito do Ano Internacional da Química, como meio fantástico de divulgação e motivação de e/ ou para o estudo da Química.

Está agendada uma nova representação no Teatro Constantino Nery em Matosinhos e ainda no Auditório de Gaia, em datas a anunciar.

Ainda no âmbito do Ano Internacional da Química, este mesmo grupo de professores está a preparar uma Tertúlia de Química, que incluirá um jantar, aberto a todos os interessados, professores, alunos, investigadores, etc., e que terá lugar no Café Guarany, situado na Avenida dos Aliados na cidade do Porto. Os interessados em participar poderão contactar a professora Lourdes Leitão - 917584775 ou mlourdesleitao@gmail.com.

\section{Lourdes Leitão, Conceição Mendonça, Fátima Sousa e Jorge Vieira (mlourdesleitao@gmail.com)}

Responsáveis pela concepção/dinamização do projecto "O Grande Musical da Química"

\section{Falácia, de Carl Djerassi}

\section{Q Ano Internacional da QUIIMICA 2011 \\ INVULGAR - que não é vulgar, co- mum; especial, raro, incomum (Dic. Houassis).}

... pois é. FALÁCIA não é um espectáculo qualquer mas, na realidade será um espectáculo INVULGAR!...

Invulgar porque não é uma coisa que se veja todos os dias. Invulgar porque talvez nunca mais volte a ter a possibilidade de ver.

Carl Djerassi, famoso químico e escritor norte-americano, assina o texto. Manuel João Monte, Professor Associado da Faculdade de Ciências da U.Porto (FCUP), fez a respectiva tradução para português. A companhia Seiva Trupe dá-Ihe corpo. É desta combinação que resulta "Falácia", título da peça que, no próximo dia 28 de Outubro, vai ser levada à cena no Teatro do Campo Alegre.

Inserida nas comemorações do Centenário da U.Porto e no programa preparado pelo Departamento de Química da Faculdade de Ciências da U.Porto para assinalar o Ano Internacional da Química, "Falácia" aborda temas transversais abrangendo a Arte, a Ciência (em particular a química) e a Ética.

Nesta peça - FALÁCIA - há um debate vivo, audacioso e cativante, com sentimentos amorosos a cruzarem-se e a prender o espectador pelo "bico". Num importante museu europeu, em Viena de Áustria, encontra-se a estátua de um rapaz nu, atribuída à era romana e que é a jóia da coroa do museu. Mas a ciência, através da química, desmistifica aquela era. E o valor artístico da obra, para além da data da sua feitura? - Aqui está um espectá- culo para quem se interessa por tudo que é importante na vida mas, muito especialmente, para quem se interessa por QUÍMICA e/ou MUSEOLOGIA.

Mas quem é Carl Djerassi? - Muito rapidamente: este génio, para além de ser autor de importantes obras teatrais, é um dos poucos cientistas norte-americanos que mereceram tanto a National Medal of Science (em 1973, pela primeira síntese de um anticoncepcional oral esteróide - a "pílula") e a National Medal of Technology. Entre as muitas dezenas de homenagens e títulos, recebeu o Prémio Wolf de Química, o primeiro prémio para a Aplicação Industrial da Ciência, conferido pela Academia Nacional de Ciências, e o mais importante prémio da American Chemical Society, a medalha Priestley.

Vanda Capitolino (quimica2011@spq.pt) www.spq.pt/quimica2011 